\title{
Prevalence of metabolic syndrome in women with polycystic ovarian syndrome: an observational study in a tertiary care centre in Pondicherry, India
}

\author{
Indu N. R. ${ }^{1 *}$, Hiremath P. B. ${ }^{1}$, Urmi Sanyal ${ }^{1}$, Shilpa $^{1}$, Rohini ${ }^{1}$, Reshma Hiremath ${ }^{2}$
}

\author{
${ }^{1}$ Department of Obstetrics and Gynecology, Sri Venkateshwaraa Medical College Hospital and Research Centre, \\ Pondicherry, India \\ ${ }^{2}$ Department of Obstetrics and Gynecology, Mapusa, Goa, India
}

Received: 11 July 2018

Accepted: 06 August 2018

\author{
*Correspondence: \\ Dr. Indu NR, \\ E-mail: indujeyanthi@gmail.com
}

Copyright: ( $)$ the author(s), publisher and licensee Medip Academy. This is an open-access article distributed under the terms of the Creative Commons Attribution Non-Commercial License, which permits unrestricted non-commercial use, distribution, and reproduction in any medium, provided the original work is properly cited.

\begin{abstract}
Background: Polycystic Ovarian Syndrome (PCOS) is a multifactorial, polygenic and multisystem endocrine disorder affecting women in reproductive age. PCOS diagnosis is based on 2003 Rotterdam criteria It has been noted that hyperinsulinemia is a central factor in the pathogenesis of PCOS. Many studies show evidence of a critical link between PCOS and Metabolic Syndrome (MBS).

Methods: It was a hospital - based observational study done over a period of one year with a sample size of 177.An observational study was done in patients satisfying the inclusion and exclusion criteria. After taking informed and written consent, history was obtained from the patient to know the age, socioeconomic status, present and past clinical history, menstrual and obstetric history, personal and family history and any other history as deemed necessary. Patient was clinically assessed to know the height, weight, body mass index.

Results: The prevalence of MBS was 37.2\%. The commonest age group was between 25- 35 years. There is no statistical association between educational qualification, economic status and the prevalence of MBS and There no significant association between the presence of acne, androgenic aloepecia and the presence of PCOS.While the presence of increased waist circumference $>88 \mathrm{cms}$, USG findings consistent with PCOS, high blood pressure > 130/85 mm of $\mathrm{Hg}$, elevated FBS $>110 \mathrm{mg} / \mathrm{dl}$, low HDL $<50 \mathrm{mg} / \mathrm{dl}$ were statistically significant.

Conclusions: The results can be used to formulate a screening policy for metabolic syndrome, particularly in the low resource settings of developing countries.
\end{abstract}

Keywords: Hirsutism, Hypertension, Metabolic syndrome, Menstrual irregularities, Obesity, Polycystic ovaries

\section{INTRODUCTION}

Polycystic Ovarian Syndrome (PCOS) is a multifactorial, polygenic and multisystem endocrine disorder affecting $12-21 \%$ of women in reproductive age. PCOS diagnosis is based on 2003 Rotterdam criteria which is characterized by hyperandrogenism (clinical/ biochemical), menstrual irregularities (oligomenorrhoea, amenorrhoea and menometrorrhagia) and polycystic ovaries. According to
Rotterdam criteria PCOS is diagnosed in a woman who is having 2 out of above mentioned 3 criteria. A diagnosis made on the basis of above criteria estimates the prevalence of PCOS to be as high as 15 to $20 \%$. It has been noted that hyperinsulinemia is a central factor in the pathogenesis of PCOS. ${ }^{1}$ Many studies show evidence of a critical link between PCOS and Metabolic Syndrome (MBS).$^{1-5}$ In recent years, MBS is diagnosed based on the International Diabetes Federation definition. This 
definition consists of raised triglycerides more than or equal to $150 \mathrm{mg} / \mathrm{ml}$, HDL cholesterol less than $50 \mathrm{mg} /$ $\mathrm{dl}$, raised blood pressure of 130/85 $\mathrm{mm}$ of $\mathrm{Hg}$ and raised fasting plasma glucose more than $100 \mathrm{mg} / \mathrm{ml}$. According to the new MBS definition, for a south east Asian woman to be defined as having MBS, she must have central obesity characterised by waist circumference $>80 \mathrm{~cm}$. In case BMI $>30 \mathrm{~kg} / \mathrm{m}^{2}$, central obesity can be assumed, and waist circumference is not considered for the definition.

It is being observed in many Asian and Western studies that there is overlapping between PCOS and MBS. Both these syndromes are common risk factors for adult onset diseases like Type II diabetes mellitus and cardiovascular diseases. ${ }^{6,7,8}$ The knowledge of this demands the need to do further research on the prevalence of MBS in PCOS women and to measure the strength of their association in the Indian society. This will help us to make an attempt in modifying the lifestyle of affected women and thereby reduces the risk of long term sequelae.

\section{METHODS}

It was a hospital - based observational study done over a period of one year on 177 patients attending the OPD in $\mathrm{SVMCH}$ and RC. The following were the inclusion and exclusion criteria

\section{Inclusion criteria}

- All women irrespective of their parity

- History of irregular menses

- Presence of hirsutism

- Ultrasound diagnosis of PCOS

- Age between 15 to 35 years

- Women who have given their consent to be a part of this study

\section{Exclusion criteria}

- Pregnant women

- Age $<15$ years or $>35$ years

- Women who are already diagnosed to have hypothyroidism, hyperprolactinemia, cushing's syndrome, non-classical - congenital adrenal hyperplasia

- Women who have not given their consent to be a part of this study

History was taken from the patient to know the age, socioecomic status, present and past clinical history, menstrual and obstetric history, personal and family history and any other history as deemed necessary. Patient was clinically assessed to know the height, weight, body mass index, waist circumference and evidence of hyperandrogenism. Hyperandrogenism is assessed by the presence of acne,hirsutism (FerrimanGallaway score >8) and insulin resistance by acanthosis nigricans. The following biochemical investigations were done in all patients
- Triglyceride levels

- HDL

- Fasting glucose

The results of the investigations were organised into continuous and categorical variables and their association was identified using unpaired student $t$ test. Chi square test was done and a $\mathrm{P}$ value of $<0.05$ was considered as significant to arrive at the results.

\section{RESULTS}

The prevalence of MBS was $37.2 \%$. The commonest age group was between 25-35 years. There is no statistical association between educational qualification, economical status and the prevalence of MBS. Table 1 shows among the 177 study participants majority were in the age groups of 25 to 35 years $(54.2 \%)$.

Table 1: Age distribution among study participants.

\begin{tabular}{|l|l|l|}
\hline Age & Frequency & Percent \\
\hline $15-25$ & 81 & 45.8 \\
\hline $26-35$ & 96 & 54.2 \\
\hline Total & 177 & 100 \\
\hline
\end{tabular}

Table 2, more than $67 \%$ were completed their degree. $36.7 \%$ were completed their postgraduate / professional degrees followed $31.1 \%$ were undergraduate degrees.

Table 2: Educational status of study participants.

\begin{tabular}{|l|l|l|}
\hline Education & Frequency & Percent \\
\hline High School & 27 & 15.3 \\
\hline HSC/Dip & 30 & 16.9 \\
\hline UG & 55 & 31.1 \\
\hline PG/Prof & 65 & 36.7 \\
\hline Total & 177 & 100 \\
\hline
\end{tabular}

Table 3 shows that $47.5 \%$ were in Upper class and $35.6 \%$ were in upper middle class by modified Kuppusamy scale. $16.9 \%$ were in middle class and there were no lower socio-economic class participants.

Table 3: Socio economic status of study participants.

\begin{tabular}{|lll|}
\hline SES & Frequency & Percent \\
\hline I & 84 & 47.5 \\
\hline II & 63 & 35.6 \\
\hline III & 30 & 16.9 \\
\hline Total & 177 & 100 \\
\hline
\end{tabular}

The prevalence of central obesity with a waist circumference of $>88 \mathrm{cms}$ was $37.3 \%$. Table 4 explains that $66(37.3 \%)$ study participants had waist circumference more than $88 \mathrm{~cm}$, which signifies more than one third were in obese state. There was no significant association between the presence of acne, 
androgenic aloepecia and the presence of PCOS in present study.

Table 4: Distribution of waist circumferences among study participants.

\begin{tabular}{lll} 
Waist Circumferences & Frequency & Percent \\
\hline Up to $88 \mathrm{~cm}$ & 111 & 62.7 \\
\hline More than $88 \mathrm{~cm}$ & 66 & 37.3 \\
\hline Total & 177 & 100 \\
\hline
\end{tabular}

Table 5 explains that prevalence of Metabolic Syndrome was $37.3 \%$ (i.e.) 66 out of 177 were diagnosed Metabolic Syndrome among study participants.

Table 5: Distribution of metabolic syndrome among study participants.

\begin{tabular}{|lll|}
\hline Metabolic Syndrome & Frequency & Percent \\
\hline Present & 66 & 37.3 \\
\hline Absent & 111 & 62.7 \\
\hline Total & 177 & 100 \\
\hline
\end{tabular}

Table 6 explains that $81.9 \%$ were suffering with PCOS, HDLC was classified with cut off value 50; among participants $82(46.3 \%)$ were had HDLC $<50$ and 95 $(53.7 \%)$ had more than 50 .

Table 6: Lab investigations details.

\begin{tabular}{|lll|}
\hline Features & Frequency & Percent \\
\hline USG & & \\
\hline B/L PCOS & 145 & 81.9 \\
\hline NAD & 32 & 18.1 \\
\hline Total & 177 & 100 \\
\hline HDLC & \\
\hline$<50$ & 82 & 46.3 \\
\hline$\geq 50$ & 95 & 53.7 \\
\hline Total & 177 & 100 \\
\hline FBS & & \\
\hline$<=110$ & 169 & 95.5 \\
\hline$>110$ & 8 & 4.5 \\
\hline Total & 177 & 100 \\
\hline TGL & & \\
\hline$<150$ & 111 & 62.7 \\
\hline$>=150$ & 66 & 37.3 \\
\hline Total & 177 & 100 \\
\hline & & \\
\hline
\end{tabular}

Eight (4.5\%) had more than 110 as fasting blood sugar value where in $95.5 \%$ had normal FBS. TGL was classified with cut off value 150, $66(37.3 \%)$ had more than 150 and $111(62.7 \%)$ had normal cholesterol level.

Table 7 describes that there was significant difference between mean Systolic blood pressure and Diastolic blood pressure between the cases and controls ( $p<0.01$ ). Similarly, Triglycerides also had significant difference in metabolic syndrome $(\mathrm{p}=0.0001)$.
Table 7: Comparison of Metabolic syndrome with control in Lab findings.

\begin{tabular}{|l|llll|}
\hline & $\begin{array}{l}\text { Metabolic Syndrome } \\
\text { Present } \\
(\mathbf{n = 6 6})\end{array}$ & $\begin{array}{l}\text { Absent } \\
(\mathbf{n = 1 1 1})\end{array}$ & $\mathrm{t}$ & $\mathrm{p}$ \\
\hline SBP & $129.7 \pm 0.72$ & $119.7 \pm 1.44$ & 52.42 & 0.0001 \\
\hline DBP & $88.97 \pm 1.01$ & $80.13 \pm 1.3$ & 47.4 & 0.0001 \\
\hline $\begin{array}{l}\text { Tri- } \\
\text { glycerides }\end{array}$ & $182.8 \pm 11.24$ & $122.29 \pm 9.79$ & 37.6 & 0.0001 \\
\hline FBS & $97.47 \pm 13.04$ & $93.59 \pm 8.44$ & 2.4 & 0.02 \\
\hline
\end{tabular}

Table 8 explains that $87.8 \%$ of the cases had fasting level more than 110, which shows significant association between fasting blood sugar level with metabolic syndrome $($ chi $\mathrm{sq}=11.42, \mathrm{p}=0.001)$.

Table 8: Association of metabolic syndrome with fasting blood sugar level.

\begin{tabular}{|c|c|c|c|c|c|}
\hline \multirow{2}{*}{ FBS } & \multicolumn{3}{|c|}{ Metabolic Syndrome } & \multirow{2}{*}{$\begin{array}{l}\text { Chi } \\
\text { sq }\end{array}$} & \multirow[b]{2}{*}{ p } \\
\hline & Present & Absent & Total & & \\
\hline$<=110$ & $58(87.8 \%)$ & 111 & 169 & \multirow{3}{*}{11.42} & \multirow{3}{*}{$\begin{array}{l}0.00 \\
1\end{array}$} \\
\hline$>110$ & $8(12.2 \%)$ & 0 & 8 & & \\
\hline Total & 66 & 111 & 177 & & \\
\hline
\end{tabular}

Table 9 explains that $84.8 \%$ of the cases had HDLC $<50$ wherein $76.6 \%$ with HDLC $>50$ in control, which shows significant association between HDLC with metabolic syndrome $($ chi $s q=60.36, p=0.0001)$.

Table 9: Association of metabolic syndrome with HDL.

\begin{tabular}{|c|c|c|c|c|c|}
\hline \multirow{2}{*}{ HDLC } & \multicolumn{3}{|c|}{ Metabolic Syndrome } & \multirow{2}{*}{$\begin{array}{l}\text { Chi } \\
\text { sq }\end{array}$} & \multirow{2}{*}{$\mathbf{p}$} \\
\hline & Present & Absent & Total & & \\
\hline$<50$ & $56(84.8)$ & $26(23.4)$ & 82 & \multirow{3}{*}{60.36} & \multirow{3}{*}{$\begin{array}{l}0.000 \\
1\end{array}$} \\
\hline$\geq 50$ & $10(15.2)$ & $85(76.6)$ & 95 & & \\
\hline Total & 66 & 111 & 177 & & \\
\hline
\end{tabular}

Table 10 explains that $89.4 \%$ had metabolic syndrome among PCOS and $77.5 \%$ of control also had PCOS even then there was significant association between USG with metabolic syndrome $($ chi $\mathrm{sq}=3.9, \mathrm{p}=0.04)$.

Table 10: Association of Metabolic syndrome with USG.

\begin{tabular}{|c|c|c|c|c|c|}
\hline \multirow{2}{*}{ USG } & \multicolumn{3}{|c|}{ Metabolic Syndrome } & \multirow{2}{*}{$\begin{array}{l}\text { Chi } \\
\text { sq }\end{array}$} & \multirow[b]{2}{*}{$\mathbf{p}$} \\
\hline & Present & Absent & Total & & \\
\hline B/L PCOS & $59(89.4)$ & $86(77.5)$ & 145 & \multirow{3}{*}{3.9} & \multirow{3}{*}{0.04} \\
\hline NAD & $7(10.6)$ & $25(22.5)$ & 32 & & \\
\hline Total & 66 & 111 & 177 & & \\
\hline
\end{tabular}

Table 11 shows that there was no significant association between Androgenic Aloepecia and metabolic syndrome $(\mathrm{p}=0.8)$. Table 12 shows that there was no significant association between Acne and metabolic syndrome ( $\mathrm{p}=$ $0.8)$ 
Table 11: Association of metabolic syndrome with androgenic aloepecia.

\begin{tabular}{|lllll|l|}
\hline Androgenic & Metabolic Syndrome & Chi & p \\
aloepecia & Present & Absent & Total & sq & p \\
\hline Present & 22 & 35 & 57 & & \\
Absent & 44 & 76 & 120 & 0.06 & 0.8 \\
\hline Total & 66 & 111 & 177 & & \\
\hline
\end{tabular}

Table 12: Association of metabolic syndrome with acne.

\begin{tabular}{|llllll|}
\hline \multirow{2}{*}{ Acne } & \multicolumn{2}{l}{ Metabolic Syndrome } & Chi & p \\
\cline { 1 - 4 } & Present & Absent & Total & sq & \\
\hline Present & 22 & 35 & 57 & & \\
Absent & 44 & 76 & 120 & 0.06 & 0.8 \\
\hline Total & 66 & 111 & 177 & & \\
\hline
\end{tabular}

Table 13 explains that $100 \%$ significant association between waist circumference with metabolic syndrome $($ chi $\mathrm{sq}=172.7, \mathrm{p}<0.01)$.

Table 13: Association of metabolic syndrome with waist circumference.

\begin{tabular}{|c|c|c|c|c|c|}
\hline \multirow{2}{*}{$\begin{array}{l}\text { Waist } \\
\text { circumference }\end{array}$} & \multicolumn{3}{|c|}{ Metabolic Syndrome } & \multirow{2}{*}{$\begin{array}{l}\text { Chi } \\
\text { sq }\end{array}$} & \multirow{2}{*}{$\mathbf{p}$} \\
\hline & Present & Absent & Total & & \\
\hline Up to $88 \mathrm{~cm}$ & 0 & 111 & 111 & \multirow{3}{*}{172.7} & \multirow{3}{*}{0.0001} \\
\hline $\begin{array}{l}\text { More than } 88 \\
\mathrm{~cm}\end{array}$ & 66 & 0 & 66 & & \\
\hline Total & 66 & 111 & 177 & & \\
\hline
\end{tabular}

Table 14 shows that there was no statistical association between Socio economic status with metabolic syndrome $($ chi $\mathrm{sq}=2.2, \mathrm{p}=0.3)$.

Table 14: Association of Metabolic syndrome with SES.

\begin{tabular}{|c|c|c|c|c|c|}
\hline \multirow{2}{*}{ SES } & \multicolumn{3}{|c|}{ Metabolic Syndrome } & \multirow{2}{*}{$\begin{array}{l}\text { Chi } \\
\text { sq }\end{array}$} & \multirow[b]{2}{*}{ p } \\
\hline & Present & Absent & Total & & \\
\hline I & 34 & 50 & 84 & \multirow{4}{*}{2.2} & \multirow{4}{*}{0.3} \\
\hline II & 19 & 44 & 63 & & \\
\hline III & 13 & 17 & 30 & & \\
\hline Total & 66 & 111 & 177 & & \\
\hline
\end{tabular}

Table 15 explains that $100 \%$ significant association between blood pressure with metabolic syndrome (chi sq $=172.7, \mathrm{p}<0.01)$. Table 16 explains that $100 \%$ significant association between TGL with metabolic syndrome $(\mathrm{chi} s q=172.7, \mathrm{p}<0.01)$. The difference in fasting blood sugar level was statistically significant $(\mathrm{p}=0.02)$. USG findings were consistently associated with PCOS. $87.8 \%$ of the cases had fasting level more than 110 , which shows significant association between fasting blood sugar level with metabolic syndrome $(\mathrm{chi} \mathrm{sq}=$ $11.42, \mathrm{p}=0.001), 87.8 \%$ of the cases had fasting level more than $110,31.6 \%$ had a high SBP of $>130 \mathrm{~mm}$ of $\mathrm{Hg}$ while $37.3 \%$ had high DBP of $>85 \mathrm{~mm}$ of $\mathrm{Hg}$ and there is a $100 \%$ significant association of high BP with PCOS.
Table 15: Association of Metabolic syndrome with BP.

\begin{tabular}{|lllllll|}
\hline BP & \multicolumn{2}{l}{ Metabolic Syndrome } & Chi & p \\
Normal & 0 & 111 & 111 & & \\
Elevated & 66 & 0 & 66 & 172.7 & 0.0001 \\
\hline Total & 66 & 111 & 177 & & \\
\hline
\end{tabular}

$87.8 \%$ of the cases had fasting level more than 110 , which shows significant association between fasting blood sugar level with metabolic syndrome (chi $\mathrm{sq}=$ 11.42, $\mathrm{p}=0.001) .84 .8 \%$ of the cases had HDL $<50$ wherein $76.6 \%$ with HDL $>50$ in control, which shows significant association between HDL with metabolic syndrome $(\mathrm{chi} \mathrm{sq}=60.36, \mathrm{p}=0.0001)$. Increased TGL > $150 \mathrm{mg} / \mathrm{dl}$ showed a $100 \%$ significant association with metabolic syndrome $($ chi sq $=172.7, \mathrm{p}<0.01)$.

Table 16: Association of Metabolic syndrome with TGL.

\begin{tabular}{|c|c|c|c|c|c|}
\hline & \multicolumn{3}{|c|}{ Metabolic Syndrome } & \multirow{2}{*}{$\begin{array}{l}\text { Chi } \\
\text { sq }\end{array}$} & \multirow{2}{*}{ p } \\
\hline TGL & Present & Absent & Total & & \\
\hline$<150$ & 0 & 111 & 111 & \multirow{3}{*}{172.7} & \multirow{3}{*}{0.0001} \\
\hline$>=150$ & 66 & 0 & 66 & & \\
\hline Total & 66 & 111 & 177 & & \\
\hline
\end{tabular}

\section{DISCUSSION}

Present study shows that $37.2 \%$ of women with metabolic syndrome had PCOS. This is closely related to the observations of $33.4 \%$ and $47.3 \%$ prevalence made by Ehrmann et al and Dokras et al respectively. ${ }^{9-13}$ The age adjusted prevalence of MBS has shown that women in between 25-35 years have the highest prevalence (54\%) of MBS. ${ }^{14,15,16}$ Studies by Dey Ramprasad et al also shows a high prevalence of $71.5 \%$ in the same age group. More than $67 \%$ of women with PCOS had completed their degree, $36.7 \%$ were completed their postgraduate / professional degrees followed $31.1 \%$ had undergraduate degrees. Socio-economically $47.5 \%$ were in Upper class and $35.6 \%$ were in upper middle class by modified Kuppusamy scale, $16.9 \%$ were in middle class and there were no lower socioeconomic class participants. This shows that there was no statistical association between socioeconomic status and metabolic syndrome although it is believed that women with sedentary jobs belonging higher socioeconomic class are more prone for MBS. The prevalence of central obesity with a waist circumference of $>88 \mathrm{cms}$ was $37.3 \%$, which signifies that more than one-third were obese and there is $100 \%$ significant association between MS and PCOS. ${ }^{17,18,19}$ This suggests that Indian women rather should have a different cut-off value for WC. Androgen excess may support the presence of an unfavorable metabolic state leading to dyslipidemia and central distribution of fat (android pattern). In obese women, excess insulin and androgens may contribute to the development of the PCOS and metabolic syndrome. The android pattern of fat distribution may be the result as well as the cause of 
hyperandrogenism, setting up a vicious circle of hyperinsulinism, hyperandrogenism, central adiposity, and metabolic abnormalities. However, there was no significant association between the presence of acne, androgenic aloepecia and the presence of PCOS in present study.

In present study, with a significant $p$ value of 0.04 , there was an association between USG findings and PCOS. This suggests that USG can be a helpful modality in diagnosing PCOS. $31.6 \%$ had a high SBP of $>130 \mathrm{~mm}$ of $\mathrm{Hg}$ while $37.3 \%$ had high DBP of $>85 \mathrm{~mm}$ of $\mathrm{Hg}$ and there is a $100 \%$ significant association of high BP with PCOS. $87.8 \%$ of the cases had fasting level more than 110, which shows significant association between fasting blood sugar level with metabolic syndrome (chi sq = $11.42, \mathrm{p}=0.001)$.

$84.8 \%$ of the cases had HDL $<50$ wherein $76.6 \%$ with HDL $>50$ in control, which shows significant association between HDL with metabolic syndrome (chi sq $=60.36$, $\mathrm{p}=0.0001)$. Kavita et al have also found similar positive associations with a low HDL $(<50 \mathrm{mg} / \mathrm{dL})$ being seen in $91.7 \%$ cases studied. ${ }^{20}$

We found a $100 \%$ significant association between TGL with metabolic syndrome (chi sq $=172.7, \mathrm{p}<0.01$ ). Screening all women with PCOS for the positively associated factors would be ideal but this is not always practical, especially in a low-resource scenario. Identifying risk factors for screening would be an alternate strategy. Our results suggest that women having any of the following risk factors: age more than 25 or with central obesity waist-hip ratio $>0.85$, are at a greater risk of having the metabolic syndrome. However, the results need to be cautiously interpreted as the present study has certain limitations. The study was done at a tertiary care centre without use of a control group of nonPCOS women for comparison and the sample size was estimated taking a precision of $9 \%$ of the true value. ${ }^{21,22}$ A larger sample size will be required for a more precise estimate of the prevalence of metabolic syndrome. We were unable to find any published data from the Indian subcontinent using the modified AHA/NHLBI ATP III (2005) criteria; hence, comparison was impossible.

\section{CONCLUSION}

The prevalence of metabolic syndrome in present study was $37.2 \%$, which constitutes more than a third of the women diagnosed with PCOS. This implies that it is mandatory to screen all the women with PCOS for features of metabolic syndrome. In present study, age $>25$ years and presence of central obesity (waist-hip ratio $>0.85$ ) were identified as risk factors for metabolic syndrome. There is a significant association of PCOS with high BP, low HDL levels, elevated FBS, high TGL and consistent USG findings. These results can be used to formulate a screening policy for metabolic syndrome, particularly in low resource settings in developing countries.

Funding: No funding sources

Conflict of interest: None declared

Ethical approval: The study was approved by the Institutional Ethics Committee

\section{REFERENCES}

1. Dey R, Mukherjee S, Roybiswas R, Mukhopadhyay A, Biswas SC. J Obstet Gynaecol India. 2011;61(2):176-81.

2. Mandrelle K, Kamath MS, Bondu DJ, Chandy A, Aleyamma T, George K. Prevalence of metabolic syndrome in women with polycystic ovary syndrome attending an infertility clinic in a tertiary care hospital in south India. J Hum Reprod Sci. 2012;5(1):26-31.

3. Moini A, Javanmard F, Eslami B, Aletaha N. Prevalence of metabolic syndrome in polycystic ovarian syndrome women in a hospital of Tehran. Iran J Reprod Med. 2012;10(2):127-30.

4. Kandaraki E, C Christakou, E Diamanti. Metabolic syndrome and polycystic ovary syndrome and vice versa. Arq Bras Endocrinol Metabol. 2009;53(2):227-37.

5. Barber MT, McCarthy MI, Franks S, Wass JAH. Metabolic syndrome in polycyctic ovary syndrome. Pol J Endocrinol. 2007;(58)1:34-41.

6. Akshaya S., Ratnaboli Bhattacharya. Comparative study of clinical profile of lean and obese polycystic ovary syndrome women Int J Reprod Contracept Obstet Gynecol. 2016;5(8):2530-3.

7. Dokras A. Cardiovascular disease risk in women with PCOS. Steroids. 2013;31;78(8):773-6.

8. Mak W, Dokras A. Polycystic ovarian syndrome and the risk of cardiovascular disease and thrombosis. In Sem Thromb Hemostat. 2009;35(7):13-20.

9. The Rotterdam ESHRE/ASRM-Sponsored PCOS Consensus Workshop Group. Revised 2003 consensus on diagnostic criteria and long-term health risks related to polycystic ovary syndrome. Fertil Steril. 2004;81:19-25.

10. Azziz R, Woods KS, Reyna R, Key TJ, Knochenhauer ES, Yildiz BO. The prevalence and features of the polycystic ovary syndrome in an unselected population. J Clin Endocrinol Metab. 2004;89(6):2745-9.

11. Legro RS, Kunselman AR, Dodson WC, Dunaif A. Prevalence and predictors of risk for type 2 diabetes mellitus and impaired glucose tolerance in polycystic ovary syndrome:a prospective controlled study in 254 affected women. J Clin Endocrinol Metab 1999;84(1):165-9.

12. Talbott EO, Guzick DS, Sutton-Tyrrell K, McHughPemu KP, Zborowski JV, Remsberg KE et al Evidence for association between polycystic ovary syndrome and premature carotid atherosclerosis in 
middle-aged women. Arterioscler Thromb Vasc Biol. 2000;20(11):2414-21.

13. Pierpoint T, McKeigue PM, Isaacs AJ, Wild SH, Jacobs HS. Mortality of women with polycystic ovary syndrome at long term follow-up.J Clin Epidemiol. 1998;51(7):581-6.

14. HaeffnerSM, ValdezRA, HazudaHP, Mitchell BD, Morales PA, Stern MP. Prospective analysis of the insulin-resistance syndrome (syndrome $\mathrm{X}$ ). Diabetes. 1992;41:715-22.

15. Reaven GM. Role of insulin resistance in human disease. Diab. 1988;37(12):1595-607.

16. Grundy SM, Becker D, Clark LT, Cooper RS, Denke MA, Howard J, et al. Third report of the National Cholesterol Education Program (NCEP) expert panel on detection, evaluation, and treatment of high blood cholesterol in adults (Adult Treatment Panel III) final report.Circulat. 2002;106(25):3143-421

17. Alberti KG, Zimmet P, Shaw J. The metabolic syndrome: a new worldwide definition. Lancet. 2005;366(9491):1059-62.

18. Ehrmann DA, Liljenquist DR, Kasza K, Azziz R, Legro RS, Ghazzi MN, PCOS/Troglitazone Study Group. Prevalence and predictors of the metabolic syndrome in women with polycystic ovary syndrome. J Clinic Endocrinol Metabol. 2006;91(1):48-53.

19. Dokras A, Bochner M, Hollinrake E, Markham S, VanVoorhis B, Jagasia DH. Screening women with polycystic ovary syndrome for metabolic syndrome. Obstet Gynecol. 2005;106(1):131-7.

20. Rabelo AM, Vick MR. Association between the PCOS and the metabolic syndrome in Puertorico.PR Health Sci J. 2005;24(3):203-6.

21. Apridonidze T, Essah PA, Iuorno MJ, Nestler JE. Prevalence and char- acteristics of the metabolic syndrome in women with polycystic ovary syndrome. J Clin Endocrinol Metab. 2005;90:192935.

22. Misra A, Wasir JS, Pandey RM. An evaluation of candidate definitions of the metabolic syndrome in adult Asian Indians. Diab Care 2005;28:398-403.

Cite this article as: Indu NR, Hiremath PB, Urmi S, Shilpa, Rohini, Hiremath R. Prevalence of metabolic syndrome in women with polycystic ovarian syndrome: an observational study in a tertiary care centre in Pondicherry, India. Int J Reprod Contracept Obstet Gynecol 2018;7:3774-9. 